\title{
A Study on the Qualitative Data Analysis for Customer Experience Management Strategy
}

\author{
Jinho Ahn', Jeungsun Lee*2 \\ IDinno Lab, Seoul, Republic of Korea, pibuchi@gmail.com¹, \\ Mortuary Science, Eulji University,Seongnam, Republic of Korea,jslee@eulji.ac.kr*2
}

Article History: Received: 11 January 2021; Accepted: 27 February 2021; Published online: 5 April 2021

\begin{abstract}
Securing customer experience data that creates positive emotions for customers and differentiates them from products and services from competitors is becoming important to a company's growth engine. In particular, an important factor in the management of experience data requires a qualitative-based experience data processing method to secure good experience data different from the quantitative data collection such as big data and processing method. With the emergence of the experience economy, it is very important for companies to collect and process experience data in the existing big data processing method. However, the experience data processing method based on big data that analyses the current quantitative data is difficult to provide good experience data from a corporate data strategic point of view. In particular, for corporate customer experience management, mix studies are required for analysis method of qualitative experience data to meaningfully interpret the expansive quantitative experience data of big data and phenomena and context in social science. This is because it is possible to discover the meaning of experience data by reading the context of phenomena by collecting experiences through ethnography methods such as observation or interviewing the context that could not be read in the process of processing the vast quantitative experience data of the big data method. In this study, the first processing was performed as an affinity diagram through a method of collecting experience data using ethnography method. Secondly, the effect of the qualitative experience data processing method on customer experience management, customer loyalty reinforcement, and enterprise value creation was studied. As a result, only the research hypothesis that there was a direct relationship between the affinity method and the utilization of experience data was rejected, and all the research settings set for the remaining qualitative experience data processing and utilization model were adopted.
\end{abstract}

Keywords: Qualitative Data , Big Data, Customer Experience Management(CEM), Experience Economy, Ethnography

\section{Introduction}

It is a hard time for companies to survive when they "sell only". This is because it is more important for these generations to continuously experience what they are getting than what they are doing right now. The ability to provide an engaging experience has become a real business capability. The era of experience economy has arrived[1]. Samsung Electronics declared the next 10 years as the "Age of Experience" at the Consumer Electronics Show (CES) in 2020.In addition to Samsung Electronics, global IT companies such as SAP, IBM, $\mathrm{CA}$, and Adobe are strategically launching Customer Experience Management (CEM) beyond customer analysis solution CRM (Customer Relationship Management) and focusing on experience data. As the importance of the experience economy grows, various attempts are being made to interpret customer experiences [2]. Securing customer experience data that creates positive emotions for customers and differentiates them from competitors' products and services will be the driving force behind the company's unlimited growth. Experience data management strategy is needed to help this experience data create the economic added value of the company and to improve the important decision making that the actual resources of the company are put into. In particular, an important factor in the experience data management strategy requires a qualitative based experience data processing method to secure good experience data that is different from the general data collection and processing process[3]. Companies are trying to advance from the existing Customer Relation Management (CRM) to the Customer Experience Management (CEM) field to deepen their understanding of customers [4]. However, the reality is that companies are unable to respond strategically due to their time and economic constraints. Quantitative collection based on big data, which is commonly used, interviews with ethnography rather than processing methods, data collection using observational survey methods, and affinity diagrams are primarily used to process and process humans who are the main subjects of experience data generation. This study is for the effects of qualitative experience data processing, which is secondarily processed using phenomenological method that interprets experience data, on customer experience management, customer loyalty enhancement, and corporate value creation. The research contributes companies with management difficulties in establishing customer-oriented management strategies and creating long-term profits and added value in the absence of information and strategies for customers 


\section{Literature Review}

2.1 Experience Data and Experience Economy

In general, experience occurs when a customer interacts with various elements in the service process provided by a service provider to obtain an emotional response or knowledge [5]. This data, which is a completely different pattern of data that can occur in 'interaction' rather than the 'numerical' data that appears on the surface, is called high-quality experience data. Experience data is not a concept inherent in a specific product or service, but a concept attributed to the user [6].

The quantitative data process is conducted in a relatively structured environment based on a large sample. However, as an attempt to quantify all the results, it is difficult to interpret the experience broadly from these findings. However, the qualitative-based experience data processing is mainly performed in the user's natural real environment, and it is easy to produce meaningful results even with a small sample. Rich and detailed discoveries are possible and can provide a new perspective (insight) on the problem. It is also easy to interpret the contextual relationship of empirical data [3].

Experience data has the characteristics of subjectivity, contextuality, and holistic [5]. The human experience is subjective according to the person's personality and cognitive characteristics, and the situation in which experience data occurs. It is difficult to collect meaningful data when using the general big data processing method because it is influenced by the external environment and is the overall psychological effect felt by the individual at the time of experience. Eventually, it is effective to collect and process meaningful experience data that is helpful to companies in the way of ethnography rather than the general big data processing method [7].

\subsection{Ethnography experience data collection}

Ethnography was developed at the beginning of the 20th century when scholars began scientifically studying social life and social systems, and through this method, they sought to discover fundamental truths about human nature, social cooperation, and the conduct of daily life. Ethnography, which is now used not only in anthropology, but also in sociology and business administration, focuses on what the subjects actually do, and can understand the voluntary and spontaneous actions of the subject and the context in which the actions occur. It's a very useful way to understand your customers. Ethnography, called field research, observational research, or participant observation, is an archetype of the research tradition that today falls under the category of qualitative research.

The use of ethnography in companies has the goal of considering the actual usability and usage of products and services in everyday life and cultural context, and discovering the social meaning of their use of products and services. Ethnography does not refer to a specific methodology, but shows that it connects the whole of people's daily lives to product concepts or designs. [8].

\subsection{First processing of experience data based on affinity diagram}

The empirical data is classified and analysed in an ethnography method, not analysis technology is necessary, but the technology of 'integration' is important. When the methods of analysis and integration are related, the true meaning of'organization' is possible, and the current scientific method is properly classified, summarized, and analysed, but pointed out that the problem of'integration' is not clear. He explains that solution is the way to enlightenment to generate new ideas, and talks about new concepts [9].

In the processing of the affinity diagram method, the experience data collected in the field is considered important. Field experience has been lightly considered by those who are interested in academics and theoretical aspects, but direct experience in the field has the power to create new things.

It should be noted that the researcher's prejudice is to take only data that fits the hypothesis. In addition, we must be wary of collecting data based on superficial similarity or collecting data based on the similarity of existing ready-made concepts. In the affinity diagram, it is important to accurately grasp the meaning of the data, not by applying the researcher's preconceptions, existing concepts, and prior knowledge as it is when analysing data [8].

The affinity diagram is also called the KJ method. Jiro Kawagita, a Japanese cultural anthropologist, called the KJ method after his name as one of the qualitative research methods that comprehensively organizes the subject to be explored by using the logical connection as an analysis axis [8].

\subsection{Secondary processing of experience data from a phenomenological perspective}

Experience data organized by affinity diagram is difficult to quantify and generalize independently, even if it goes through the process of data purification, and data cannot be quantified and interpreted. Therefore, in this study, the second data processing step of the phenomenological technique is important. This is a method of describing the first processed experience data to be interpreted in a text format of life as if drawn like a real customer [10-22]. 
In terms of qualitative research methodology, phenomenological research describes the experiential meaning of several individuals for a concept or phenomenon. Phenomenologists focus on describing what they have in common while experiencing phenomena [17]. In other words, the basic purpose of phenomenology is to reduce individual experiences of phenomena to descriptions of universal nature [10-23]. To achieve this goal, qualitative researchers confirm the phenomenon. The processing of experience data from a phenomenological point of view makes it possible to develop a complex technique for the essence of all experiences collected and processed. These skills consist of 'what' and 'how experienced' experience [16].

From the point of view of processing phenomenological data, the "persona" technique is also a good methodology. Persona refers to a virtual representative user who uses a product or service, and through persona, it is possible to design a user experience that suits various behaviors and situations. By using this method, instead of relying on complex data or statistical data to understand the market and users, you can feel more cognitively and closer as a personal person with a human face [3].

\subsection{Customer experience management}

Customer relationship management is to look at customers from the perspective of a company, and deals with objective information about customers, such as the customer's gender, age, residential area, and number of visits. Customer experience management is a way to see a company through the eyes of customers, and to operate a company based on the subjective experiences of customers.

Customer experience means that the customer's senses, emotions, perceptions, behaviours, and the degree of relationship affect the customer's experience [13]. Customer Experience Management means touch point management. Experiences felt at various points of contact can create or lose loyalty to the company or brand. Therefore, the most important thing in customer experience management is to establish a deep relationship between the company and the customer at the customer's contact point [15].

Experience is perceived purely from the point of view of an individual customer, the essence of which is personal and exists only in the mind of the customer. Customer experience is an internal and subjective reaction that occurs when a customer directly or indirectly interacts with a company. The moments you meet in person include purchasing, using, and receiving services from customers. Indirect moments are mainly unplanned situations, such as corporate products and services, brands, word of mouth, advertising, and news [20].

The attribute to obtain information at the point of consumption is empirical attribute, and from the perspective that the product providing such attribute is an experiential product, direct experience through the use of the brand or consumption activity. And there is also a perspective approaching with an emotional and sensuous meaning [21]

\subsection{Strengthening customer loyalty and creating added value for companies}

When the market has a lot of open space, the focus is on acquiring new customers, but as the market stagnates and transforms into a mature market, at the same time, cost reduction becomes a very important competitive factor, and how many years do you retain loyal customers? It is becoming a major concern for companies.

Customer loyalty reduces the behavioral uncertainty of a company's use of new services, instilling a sense of control over potentially uncertain transactions, encouraging future transactions, and helping to build long-term relationships [12].In fact, initial brand loyalty focused on repeat buying behavior. However, since spurious loyalty and true loyalty, which appear in the absence of other possible alternatives, cannot be distinguished, it has been argued that the behavioral loyalty resulting from such repeat purchases is insufficient [13]. In response to this criticism, a method of measuring loyalty by adding an attitude element to the behavioral element was proposed.

If customer loyalty is strengthened, it is possible to create high added value for companies. In general, added value refers to a high value newly added through the production and supply process from an economic point of view. The value of the market is not fixed, but complexly shifts according to changes in the market environment such as technology and service innovation or customer needs. Therefore, companies can also create value unique to a new company only by effectively coping with this shift of value. It is defined as a management strategy that creates customer utility more efficiently than an obsolete or obsolete business design, and shifts value to a field that realizes new value from a corporate standpoint [11].

Customers' purchasing behavior is changing from simply satisfying basic needs to social adaptation and selfexpression [18]. Accordingly, customers are constantly increasing consumption of high-value and high-valueadded products by adjusting their emotional value, and differentiated design and high-end brand image by increasing consumption consciousness that emphasizes imitation consumption, aesthetic sense, flavor and dignity. The propensity to consume value, which regards as an important selection criterion, is becoming more common [19]. 


\section{Research Model and Research Hypothesis}

\subsection{Research Model}

Thisstudy is to find out the validity of the hypothesis of correlation between qualitative experience data processing and customer experience management strategy based on theoretical research. To study this, a research model was set up as shown in the figure 1 below.

Figure 1. Research Model

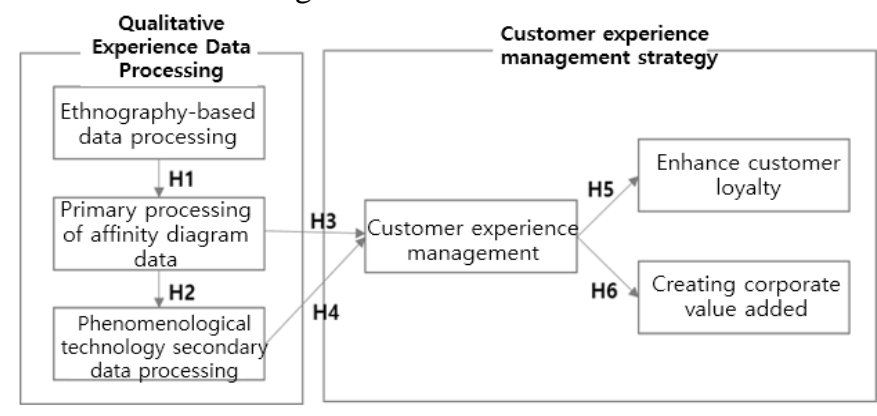

\subsection{Hypothesis Setting}

First of all, the following research hypothesis was established by using previous research cases to conduct practical verification of the effects between qualitative experience data processing procedures.

[H1] Collecting data by the ethnography method has a positive effect on the processing with the affinity diagram. [H2] Affinity diagram data primary processing is a phenomenological technique and has a positive $(+)$ effect on secondary processing of data. [H3] Affinity diagram data primary processing has a positive (+) effect on customer experience management. [H4] Secondary processing of data with phenomenological technology has a positive effect on customer.

We established the hypothesis that can prove this through the study of the causal relationship by reflecting the literature study of customer experience management, customer loyalty enhancement, and corporate value creation. [H5] Customer experience management has a positive effect on strengthening customer loyalty. [H6] Customer experience management has a positive effect on the creation of corporate value added.

\section{Empirical Analysis and Result}

\section{Research subject and data collection \\ 1.1}

This study was conducted through a questionnaire survey of 15 SMEs located in Seoul, Gyeonggi-Do, Korea. Data was collected from March 2019 to April 2019 by online survey methods for practitioners in charge of customer consultation and data processing in the marketing, information systems, and customer management departments of the target companies. The data collected in this study were analysed using the SPSS ver. 25 program.

\subsection{Characteristics of survey subjects and data collection}

The subjects used for the final analysis were inconsistent in answer, and 124 answers were used, except for 5 incorrect answers. They were 36 marketing managers (29\%), information system data processing managers 32 (26\%), and customer care department customer counsellors $56(45 \%)$. The questionnaire of this study was conducted prior to the actual survey to conduct a preliminary survey by setting 22 representatives of SMEs with experience in performing data-related tasks in February 2019 to test the feasibility of the survey items, conducting a preliminary survey, and supplementing the results. The final questionnaire was completed.

To test the research hypothesis, the reliability and validity of the measurement items were tested in the SPSS ver.25 program, and the reliability of the items constituting each factor was measured by exploratory factor analysis and Cronbach's alpha coefficient. For the proven factors, a correlation analysis was conducted to measure the interrelationship and direction.

\subsection{Validity, reliability, correlation analysis}

In this study, content validity was confirmed by various theoretical considerations based on previous studies between variables. Based on the theoretical considerations, the validity of the reference can be secured even if there are no additional tests to use the indicators tested in the previous study without modification or to use them after some modification. The conceptual validity test was conducted by exploratory factor analysis. Factor 
analysis was conducted by classifying the factors of qualitative experience data processing and customer experience management strategy with a factor load of 0.4 or more with an intrinsic value of 1.0 or more. As a result, all items were extracted in the same way as the preceding theory. The validity and reliability of the variables used in this study were tested, and the correlation between the variables was analysed.

In the correlation analysis, the correlation coefficient values of all variables showed a high correlation of 0.5 or higher, and the significance level was also statistically significant with 0.01 or higher. Therefore, it was judged that the hypothesis setting of the relationship between the independent variable and the dependent variable was meaningful, and it was judged that the items used as the normally validity were valid because the direction between the variables coincided with the direction of the research hypothesis.

To test the research hypothesis, the reliability and validity of the measurement items were tested in the SPSS program, and the reliability of the items constituting each factor was measured by exploratory factor analysis and Cronbach's alpha coefficient. Correlation analysis was performed to measure the correlation and direction of the proven factors.

\section{Results of Hypothesis Test}

For the hypothesis H1 that the data collection using the ethnography method will have a positive (+) effect on the primary processing of the data of the affinity diagram formula, the $t$ value was adopted as $4.887(p=.000)$, and the data of the ethnography method The hypothesis $\mathrm{H} 2$ that collection will have a positive effect on the secondary processing of data in a phenomenological description method has a t value of $6.143(p=.000)$

Table 1. Regression analysis when independent variable is ethnography data collection

\begin{tabular}{|c|c|c|c|c|c|}
\hline & & & & & \\
\hline $\begin{array}{l}\text { Dependent } \\
\text { var. }\end{array}$ & $\begin{array}{l}\text { Independe } \\
\text { nt Var. }\end{array}$ & $\begin{array}{l}\text { SD. } \\
\text { Error }\end{array}$ & Beta & $\mathrm{t}$ & $\begin{array}{l}\text { val } \\
\text { ue }\end{array}$ \\
\hline ary & (Contstant) & 218 & & \begin{tabular}{|c|}
4.1 \\
43 \\
\end{tabular} & $\begin{array}{l}.00 \\
0\end{array}$ \\
\hline $\begin{array}{c}\text { processing of } \\
\text { affinity diagram } \\
\text { data }\end{array}$ & $\begin{array}{l}\text { Ethnograp } \\
\text { hy data } \\
\text { collection }\end{array}$ & .059 & .616 & $\begin{array}{r}4 . . \\
887\end{array}$ & $1^{.00}$ \\
\hline & $\mathrm{R}=.616$, & $\mathrm{R}^{2}=.38$ & $\mathrm{~F}=78.9$ & $8, \mathrm{P}=$. & \\
\hline Phenomenolo & (Contstant) & .214 & & $\begin{array}{c}6.0 \\
41 \\
\end{array}$ & $0^{.00}$ \\
\hline $\begin{array}{c}\text { gical technique } \\
\text { Data } \\
\text { secondary } \\
\text { nrocessing }\end{array}$ & $\begin{array}{l}\text { Ethnograp } \\
\text { hy data } \\
\text { collection }\end{array}$ & .049 & .633 & $\begin{array}{c}6.1 \\
16\end{array}$ & $0^{.00}$ \\
\hline
\end{tabular}

In the hypothesis $\mathrm{H} 3$ that the first processing of the data in the affinity diagram formula will have a positive $(+)$ effect on the customer experience management, the $\mathrm{t}$ value was rejected as $.694(\mathrm{p}=.418)$, and the second processing of the data using the phenomenological description method. The hypothesis $\mathrm{H} 4$ that this customer experience management will have a positive $(+)$ effect has a t value of $4.835(\mathrm{p}=.000)$.

Table 2 Regression analysis when the dependent variable is customer experience management

\begin{tabular}{|c|c|c|c|c|c|c|}
\hline $\begin{array}{l}\text { Depende } \\
\text { nt var. }\end{array}$ & $\begin{array}{l}\text { Independent } \\
\text { Var. }\end{array}$ & $\begin{array}{l}\text { SD. } \\
\text { Error }\end{array}$ & $\begin{array}{l}B \\
\text { eta }\end{array}$ & $\mathrm{t}$ & $\begin{array}{l} \\
- \\
v \\
\text { alue }\end{array}$ & $\begin{array}{c}\text { toler } \\
\text { ance }\end{array}$ \\
\hline \multirow{3}{*}{$\begin{array}{r}\text { Custome } \\
\text { r experience } \\
\text { management }\end{array}$} & (constant) & .279 & & $\begin{array}{r}2 . \\
742\end{array}$ & ${ }^{.0}$ & \\
\hline & $\begin{array}{c}\text { Primary } \\
\text { processing of } \\
\text { affinity diagram } \\
\text { data }\end{array}$ & .115 & 084 & $94^{.6}$ & $18^{.4}$ & .362 \\
\hline & $\begin{array}{l}\text { Phenomenolo } \\
\text { gical technique } \\
\text { Data secondary } \\
\text { processing }\end{array}$ & .104 & 491 & $\begin{array}{r}4 . \\
835\end{array}$ & $00^{.0}$ & 394 \\
\hline
\end{tabular}

$\mathrm{R}=.686, \mathrm{R} 2=.484$, Durbin-Watson=1.827, $\mathrm{F}=39.676, \mathrm{P}=.000$ 
The hypothesis H5 that customer experience management will have a positive $(+)$ effect on strengthening customer loyalty has a $t$ value of $5.575(\mathrm{p}=.000)$, and customer experience management will have a positive $(+)$ effect on the creation of corporate added value. As for the hypothesis H6, the t value was adopted as H4,.322 (p $=.000)$.

Table 3 Regression analysis when the independent variable is customer experience management

\begin{tabular}{|c|c|c|c|c|c|}
\hline Dependent var. & $\begin{array}{l}\text { Independent } \\
\text { Var. }\end{array}$ & $\begin{array}{l}\text { SD.E } \\
\text { rror }\end{array}$ & Beta & $\mathrm{t}$ & $\begin{array}{l}\mathrm{P}- \\
\text { value }\end{array}$ \\
\hline \multirow{3}{*}{$\begin{array}{l}\text { Strengthening } \\
\text { customer loyalty }\end{array}$} & (constant) & .229 & & $\begin{array}{l}5.63 \\
9\end{array}$ & .000 \\
\hline & $\begin{array}{l}\text { Customer } \\
\text { experience } \\
\text { management }\end{array}$ & .061 & $1^{.68}$ & $\begin{array}{l}5.57 \\
5\end{array}$ & .002 \\
\hline & \multicolumn{5}{|c|}{$\mathrm{R}=.616, \mathrm{R}^{2}=.380, \mathrm{~F}=78.978, \mathrm{P}=.000$} \\
\hline \multirow{3}{*}{$\begin{array}{c}\text { Creation of } \\
\text { corporate added value }\end{array}$} & (constant) & .274 & & $\begin{array}{l}3.61 \\
8\end{array}$ & .000 \\
\hline & $\begin{array}{l}\text { customer } \\
\text { experience } \\
\text { management }\end{array}$ & .076 & $4^{.63}$ & $\begin{array}{l}4.32 \\
2\end{array}$ & .000 \\
\hline & \multicolumn{5}{|c|}{$\mathrm{R}=.634, \mathrm{R}^{2}=.402, \mathrm{~F}=88.978, \mathrm{P}=.000$} \\
\hline
\end{tabular}

In the corporate data-based customer experience management strategy, it is important to consider the harmonious consideration of qualitative experience data that meaningfully interprets the phenomena and context in social science as well as massive quantitative experience data [19]. Therefore, in this study, a qualitative-based experience data processing method and customer suspicion management strategy, which are processed based on completely different patterns of data, rather than "numerical" data that were revealed, were conducted. Thus, the hypothesis $\mathrm{H} 1 \sim \mathrm{H} 4$ was established for the data processing procedure of collecting experience data in the ethnography method, primary processing with the affinity diagram, and secondary processing of the experience data in the form of phenomenology. . In addition, we tried to verify through additional hypothesis that this qualitative method of processing experience data has a causal relationship with corporate customer experience management, customer loyalty enhancement, and corporate value creation. As a result, the hypothesis $\mathrm{H} 3$ that the experience data processed by the affinity diagram would have a direct effect on customer experience management was rejected, but the rest of the hypotheses were adopted

Table 4. Test Results of Research Hypothesis

\begin{tabular}{|c|c|c|}
\hline The indicator & $\begin{array}{c}\text { P- } \\
\text { Value }\end{array}$ & Result \\
\hline $\begin{array}{c}\text { Collecting data by the } \\
\text { ethnography method has a } \\
\text { positive effect on processing } \\
\text { with the affinity diagram }\end{array}$ & .001 & Selected \\
\hline $\begin{array}{l}\text { The primary processing of } \\
\text { the affinity diagram method is } \\
\text { a phenomenological technique } \\
\text { and has a positive effect on the } \\
\text { secondary processing of data }\end{array}$ & .000 & Selected \\
\hline $\begin{array}{l}\text { The primary processing of } \\
\text { affinity diagram data has a } \\
\text { positive (+) effect on customer } \\
\text { experience management. }\end{array}$ & .413 & Dismissed \\
\hline $\begin{array}{l}\text { Secondary processing of } \\
\text { data with phenomenological } \\
\text { technology has a positive effect } \\
\text { on customer experience } \\
\text { management }\end{array}$ & .000 & Selected \\
\hline $\begin{array}{l}\text { Customer experience } \\
\text { management has a positive } \\
\text { effect on strengthening } \\
\text { customer loyalty }\end{array}$ & & \\
\hline
\end{tabular}




\begin{tabular}{|l|l|l|}
\hline Customer experience & .000 & Selected \\
management has a positive & & \\
effect on the creation of & & \\
corporate value added & & \\
\hline
\end{tabular}

\section{Conclusion}

7.

Data is just a symbol that excludes the traces of life between people and people and classes and hierarchies in the symbol of numbers. This is a symbol that removes the context (society), and as the number cannot be a solution to a grim social system, as long as the data value is high, we must face the fact that the reality always exists in the data 'outside'. Experience data does not seek meaning from a quantitative approach that collects a large amount of data, but attention should be paid to the emotional reactions of customers that can occur in the interaction between people and people. After all, it is necessary to collect high-quality data from heterogeneous behavior patterns as customers interact with various factors. It is necessary to directly collect experience data on product and service-oriented social meanings based on the actual usage situation by investigator observation and interview methods, and gradually structure experience data of heterogeneous nature through the affinity diagram method. In the end, this work requires phenomenological processing the meaning of experience so that it is cognitively similar to the target customer of the company from the viewpoint of increasing the usability of experience data. This processed experience data has the effect of strengthening the loyalty of the customer of the company and supporting the customer experience management strategy that can support the company's creation of added value. This qualitative experience data processing know-how will be linked to the latest technological elements and serve as a catalyst to transform the company into a completely new business model.

\section{References}

1. Jinho, A. (2020). Read secret and great Data. KEPCO 2020. Vol. 561.

2. Hyun-jung C. (2019). Applying Ethnographic Research to Business Field: A Case Study of Developing a New Concept of a Home Appliance Based on the Audition Process Sampling. CrossCultural Studies, 25(2), 347-380.

3. Jinho A., JeungSun L. (2020). A Study on the direction of Funeral service focused on thick data analysis. Journal of Service Research and Studies, 10(1), 85-96.

4. Bornakke, T., Due, B. L. (2018). Big-Thick Blending: A method for mixing analytical insights from big and thick data sources. Big Data \& Society. 18(2), 1-16.

5. JaeHwa L. (2015). A Study on the Experience Economy Design in Service Management. The Korean Research Association for the Business Education, 29(6), 545-569.

6. Daeho K., Seonkyu C., Jaeshin L., Donghee S., Jaehyu A., Kyungran J., Sangwoo L., Seongchul K., Doyeun K. and Yongyun S.(2014). ICT Ecosystem, (pp. 80).Communication Books.

7. Kawakita J. (1986). KJ method: Chaotically speaking, Chuokoronsha.

8. Park A. (2018). A case study on returning students' college life.Korean Youth Study, .29(3), 5-40.

9. Van Manen, M. (2006). Writing qualitatively, or the demands of writing. Qualitative Health Research, 16, 713-722.

10. John W. C. (2010). Qualitative Inquiry and Research Design: Choosing Among Five Approaches. (pp.91-97). SAGE Press.

11. Clark M. (1994). Phenomenological Research Methods, SAGE Publication.

12. Jinsoo J., Namjae P. (2015). Development and Evaluation of UX Design Centered STEAM Career Education Program Utilizing Personas Models. Journal of the Korean Association of Information Education. 19(1), 77-86.

13. Schmitt BH. (1999). Experiential Marketing: How to Get Customers to Sense, Feel, Think, Act, and Relate to Your Company and Brands, Free Press.

14. Heesun K. (2017). A Study on Usability Improvement of Mobile Healthcare Services, International Journal of Advanced Smart Convergence (IJASC), 6(2), 72-81.

15. Yo-Seob L.(2020). Analysis of Automatic Machine Learning Solution Trends of Startups, International Journal of the Advanced Cultural Technology (IJACT). 18(2), 297-304.

16. Chang, J.Y. (2019). Bigdata Prediction Support Service for Citizen Data Scientists. Institute of Internet, Broadcasting and Communication (IIBC), 19(2), 151-159.

17. Christopher M., Andre S. (2007). Understanding Customer Experience. Harvard Business Review. $85(2), 116-157$.

18. Ju-eun Kim,(2019) An Analysis of the effect of Artificial Inteligence on Human Society, The Jurnal of the Convergence on Culthre Technology (JCCT),5(2). 177-182. 
19. Jagdish N. S. (1991). Why We Buy What We Buy: A Theory of Consumption Values.Journal of Business Research. 22(2), 159-170.

20. Pine B., J. Gilmore. (1998). Welcome to the Experience Economy. Harvard Business Review, JulyAug, 1998. 97-105.

21. Aida H., Maslin M. (2019). Factors Influencing Information Systems Adoption: A Review of the Literature, International Journal of Internet, Broadcasting and Communication (IJIBC), 11(2), 19. 26

22. Bermejo, FT (2019). Oligopolistic market modeling: the case of wood for flooring. Spain $1994-$ 2012. Cuadernos de Economía , 42 (119).

23. Casas-Rosal, JC, del Rosal, DEC, Caridad, JM, \&Tabales, JMN (2019). Real estate market in Spain: A tool for supply analysis. Cuadernos de Economía: Spanish Journal of Economics and Finance , 42 (120), 207-218. 